\title{
CROSS-SECTIONAL ASSOCIATION BETWEEN WALKING PACE AND SLEEP-DISORDERED BREATHING
}

\begin{tabular}{|c|c|}
\hline Journal: & International Journal of Sports Medicine \\
\hline Manuscript ID: & IJSM-01-2015-4702-cs.R1 \\
\hline Manuscript Type: & Clinical Sciences \\
\hline Key word: & obstructive sleep apnoea, physical activity, screening, frailty \\
\hline Abstract: & 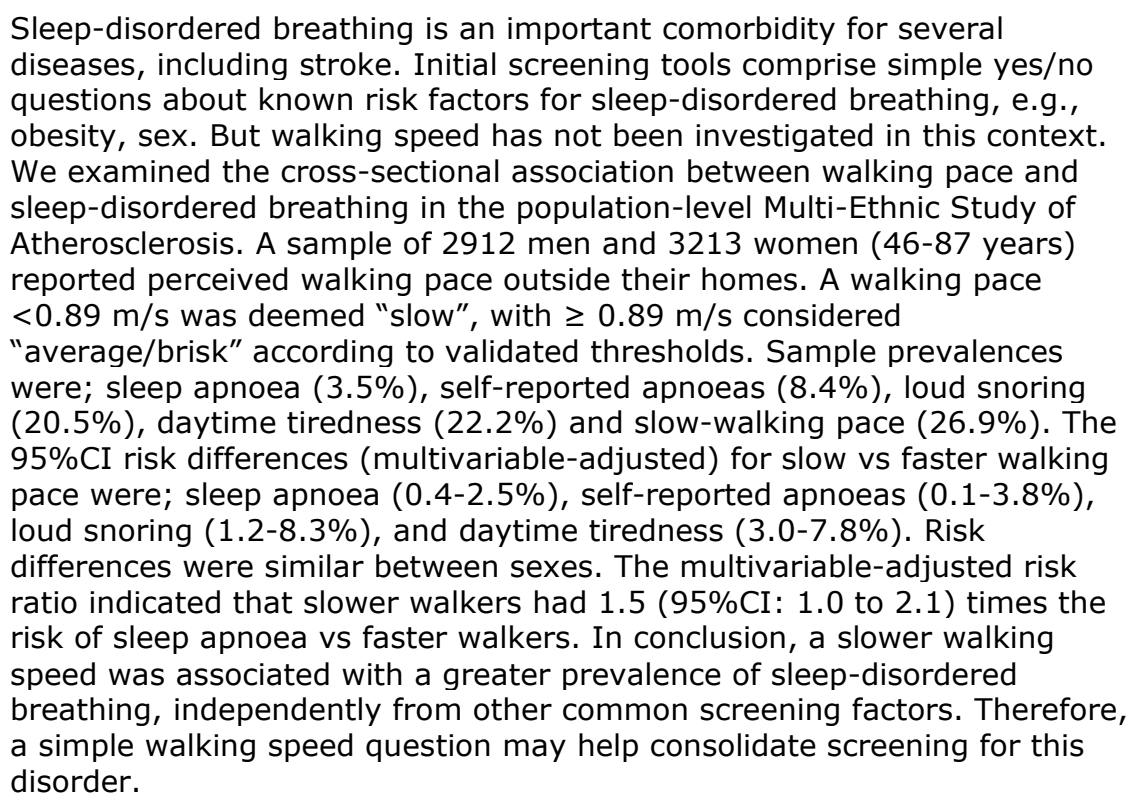 \\
\hline
\end{tabular}




\title{
CROSS-SECTIONAL ASSOCIATION BETWEEN WALKING PACE AND SLEEP. DISORDERED BREATHING
}

\begin{abstract}
Sleep-disordered breathing is an important comorbidity for several diseases, including stroke. Initial sScreening tools comprise simple yes/no questions about known risk factors for sleep-disordered breathing, e.g., obesity, sex. But walking speed has not been investigated in this context. We examined the cross-sectional association between walking pace and sleep-disordered breathing in the populationlevel Multi-Ethnic Study of Atherosclerosis. A sample of 2912 men and 3213 women (46-87 years) reported their-perceived walking pace outside their homes. A walking pace $<0.89 \mathrm{~m} / \mathrm{s}$ was deemed "slow", with $\geq 0.89 \mathrm{~m} / \mathrm{s}$ considered "average/-brisk" according to published-validated thresholds. Multivariable-adjusted risk differences and prevalence risk ratios were quantified.Sample prevalences were; sleep apnoea (3.5\%), self-reported apnoeas (8.4\%), loud snoring (20.5\%), daytime tiredness $(22.2 \%)$ and slow-walking pace $(26.9 \%)$. The $95 \% \mathrm{Cl}$ risk differences_(multivariable-

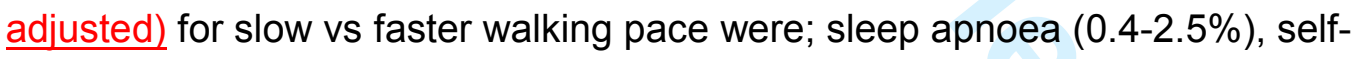
reported apnoeas $(0.1-3.8 \%)$, loud snoring (1.2-8.3\%), and daytime tiredness (3.07.8\%). Risk differences were similar between sexes. The multivariable-adjusted risk ratio indicated that slower walkers had $1.5(95 \% \mathrm{Cl}: 1.0$ to 2.1$)$ times the risk of sleep apnoea vs faster walkers. In conclusion, a slower walking speed was associated with aA greater prevalence of sleep-disordered breathing,g was independently from other common screening factorsly associated with a walking speed $<0.89 \mathrm{~m} / \mathrm{s}$. Therefore, a simple walking speed question may help consolidate screening for this disorder.
\end{abstract}




\section{Introduction}

Sleep-disordered breathing refers to a severity continuum ranging from loud snoring to physician-diagnosed obstructive sleep apnoea. Obstructive sleep apnoea is characterized by multiple losses of airway patency during sleep leading to hypoxia, hypercapnia, sleep fragmentation and increases in inspiratory efforts, all of which contribute to negative physiologic changes within the cardiovascular and pulmonary systems [1]. Obstructive sleep apnoea affects $4-9 \%$ of the adult population, but prevalence can be much higher (sometimes $>60 \%$ ) in patients with stroke, heart disease and hypertension [121]. Obstructive sleep apnoea can also lead to excessive daytime tiredness, which can compromise daily functioning, decrease workplace productivity and increase the risk of motor vehicle accidents [2ㅍz]. This presence of daytime tiredness leads to a diagnosis of obstructive sleep apnoea syndrome.

The prevalence of moderate-to-severe sleep-disordered breathing can be as high as $20 \%$ in community-living adults [7]. Screening for sleep-disordered breathing is particularly important from both public health and economic perspectives [6]. It is also important to screen for sleep-disordered breathing in patients with other underlying conditions who require surgery [1녀]. Polysomnography is the gold standard diagnostic procedure for sleep-disordered breathing severity, yet is costly and generally only available in tertiary referral sleep centres [2018]. Therefore, various screening tools have been designed for sleep-disordered breathing, such as "STOP-Bang". This particular screening tool comprises eight simple yes/no questions relating to risk factors (e.g. male sex, body mass index (BMI) $>35 \mathrm{~kg} / \mathrm{m}^{2}$ ) 
and indicators (e.g. snoring, daytime tiredness) for the disorder [5]. Some of these questions, e.g., loudness of snoring and occurrence of apnoea, are difficult to answer because they can rely on the presence of a bed partner. There are other diagnostic tools for sleep-disordered breathing including the Berlin Questionnaire and the 4-Variable Screening Tool [1ㅌ5]. No screening tool has, to date, included an item relating to physical activity.

Although the potential physiological mechanisms have not yet been fully elucidated (Figure 1), low levels of habitual physical activity are associated with worse severity of sleep-disordered breathing $[10,179,16]$. One indicator of physical activity, which is also a robust indicator of general frailty, is reported walking speed [2219]. Healthrelated thresholds for low and high walking speeds have recently been formulated [4]. Therefore, we hypothesised that a simple yes/no question, similar to those in existing screening tools, but pertaining to reported walking speed, is associated with the severity of outcomes related to sleep-disordered breathing. We tested this hypothesis with the large population-based dataset from the Multi-ethnic study of atherosclerosis (MESA).

\section{Methods}

\section{Participants}

The MESA is a large population-based study examining the early stages of cardiovascular disease. The research objectives and design have been published elsewhere [3]. The MESA study was approved by the local Institutional Review 
Boards of each participatory study site. Our cross-sectional analysis of the MESA dataset was also-approved by the local research ethics committee. This study also meets the ethical standards of the international Journal of Sports Medicine [9].

The MESA participants were 6814 men (47\%) and women (53\%) aged between 4584 years from 6 communities in the US. Participants were from 4 different ethnic groups; white (39\%), African-American (28\%), Hispanic (22\%), Chinese-American (12\%). Data for the MESA were collected during five examination points over a $12-$ year period. Data for the present study were analysed from exam 2, undertaken between 2002 and 2004.

\section{Measurement procedures}

The outcomes relating to sleep-disordered breathing were physician--diagnosed sleep apnoea, self-reported apnoeic events, loud snoring heard behind a closed door and daytime tiredness. These outcomes were measured using a self-administered sleep questionnaire, as detailed previously by Yeboah et al. [274]. Participants could choose from a list of answers for each question with 'don't know' provided as a response for apnoea and snoring items. Guidelines from the American College of Physicians indicate that polysomnography has, and continues to be used routinely for the diagnosis of obstructive sleep apnoea [18]. It is reasonable therefore to assume that participants who answered 'yes' to the question relating to physiciandiagnosed sleep apnoea had undergone polysomnography as part of their diagnostic pathway [21]. An interviewer-administered physical activity questionnaire was also completed. One question was: 'When you walk outside of your home, what is your usual pace?' Five response options were given-provided from 'no walking at all' to 
'brisk or striding'. Self-reported walking speed has been shown to be a good marker of measured walking speed in older adults in a recent large population-based study [24]. To facilitate a simple yes/no context in keeping with the traditional screening tools, a walking speed $<0.89 \mathrm{~m} / \mathrm{s}$ (or no reported walking) was classified as "slow", with $\geq 0.89 \mathrm{~m} / \mathrm{s}$ classified as "average/ brisk". The threshold used to define slow walking speed was informed by Stanaway et al. [2219], who reported that walking slower than $0.89 \mathrm{~m} / \mathrm{s}$ was predictive of mortality. The self-reporting of the relevant variables in the MESA is in the tradition of items on the current clinical STOP-Bang screening tool and facilitates a large sample of participants for data analysis. Our other study outcomes-covariates included age, sex and ethnicity. Each participant's BMI and blood pressure were measured during clinical evaluation [3].

\section{Data reduction}

All outcome variables were dichotomised in keeping with current screening tools, such as the STOP-Bang. Responses to the 'how loud is your snoring?' question in MESA were recoded into whether snoring was "extremely loud- can be heard through a closed door" or not. Responses to "how often do you feel excessively (overtly) sleepy during the day?' were recoded into never/sometimes and often/almost always. Other items, including physician-diagnosed sleep apnoea were already in a dichotomised format.

\section{Statistical Analysis}

Data analysis was completed in the Statistical Package for the Social Sciences (SPSS, version 21) and Stata (StatCorp, Texas, version 12.1). Data were analysed with multivariable-adjusted binomial regression (with an identity link function), 
providing risk differences and their confidence intervals $(95 \% \mathrm{Cl})$. Analyses were adjusted for age, sex and ethnicity. Multivariable-adjusted cox regression with a constant time-to-event variable [2] was employed to derive prevalence risk ratios and associated $95 \% \mathrm{Cls}$ for the six STOP-Bang items, as well as for our additional slow walking speed question. We defined the minimum clinically important effect as a prevalence risk ratio of 1.11 . This effect size implies that for every 10 people with sleep apnoea who have a slow walking speed there are 9 people with sleep apnoea who have a fast walking speed; that is, one in 10 sleep apnoea cases is associated with a slow walking speed. Thresholds for moderate, large, very large, and extremely large effects were deemed to be risk ratios of $1.43(10 / 7), 2(10 / 5), 3.3(10 / 3)$, and 10 (10/1), respectively.

\section{Results}

Faster walkers were, on average, 3.5 years younger and $2.3 \mathrm{~kg} / \mathrm{m}^{2}$ lower in BMI than slower walkers. Faster walkers also comprised a lower proportion of women and African-American participants, and a higher proportion of white participants (Table 1). The mean total number of medications was slightly (0.4) higher in slow walkers than in average/brisk walkers.

The prevalence of sleep-disordered breathing outcomes in the dataset is presented in Table 2. The prevalence of physician diagnosed sleep apnoea, self-reported apnoeas and loud snoring was higher in men compared with women (4.8 v $2.3 \%$,

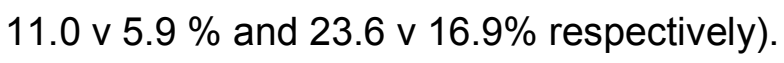


Slower walking speed was associated with an increased risk of all outcomes indicative of sleep-disordered breathing, including physician-diagnosed sleep apnoea (Table 3). These risk differences were adjusted for sex, age, and ethnic group. No substantial interactions were found between walking speed, ethnic group and sex. Risk differences were also similar when people who reported no walking at all were removed from the analyses.

We investigated whether slow walking speed was an independent risk factor for physician-diagnosed sleep apnoea compared with other yes/no type outcomes present in traditional obstructive sleep apnoeaOSA screening tools. Questions relating to apnoea incidence, and loud snoring were, as expected, the strongest independent predictors of sleep apnoea (Table 4). Body mass index was also an independent predictor of sleep apnoea (prevalence risk ratio: 1.7). Nevertheless, the strength of the independent association of slow-walking speed was approaching that of BMI. People who walked relatively slow had 1.5-times the risk of having sleep apnoea compared with people who walked at a faster pace. This prevalence risk ratio was higher than the point estimates of the prevalence risk ratios for the screening items of daytime tiredness, sex and hypertension (Table 4).

\section{Discussion}

In this large population-based study, slow-walking speed was independently associated with an increased risk of sleep-disordered breathing outcomes. A simple yes/no question relating to slow walking speed compared favourably with other items present on existing screening tools for sleep-disordered breathing, including sex, daytime tiredness and hypertension. 
The prevalence of diagnosed sleep apnoea was greater in men $(4.8 \%)$ than in women (2.3\%). Nevertheless, the multivariable-adjusted association between sex and sleep apnoea was weak and not statistically significant (Table 4), suggesting that sex-related covariates, such as BMI, might be more influential than sex per se. We also did not find a substantial interaction between sex and the slow walking speed - sleep apnoea association. Endeshaw et al. [7] also analysed a populationlevel dataset (The Cardiovascular Health Study) and reported an association between slow-walking speed and sleep-disordered breathing, but only in women. The authors reported that this sex-specific finding was unexpected, but postulated that the protective effect of female hormones on airway collapse is lost after the menopause. Endeshaw et al. [7] obtained polysomnographic data from their participants while they slept at home, allowing the quantification of the rate of apnoeas and hypopnoeas, in contrast to the self-report approach employed in the present study. Nevertheless, the sample size in the current study was substantially larger than theirs ( $\mathrm{n}=6125$ vs. 1042), providing greater precision of estimation of effects in both sexes. In agreement with our findings, data from the Wisconsin Sleep Cohort Study indicated that the association between habitual exercise and sleepdisordered breathing was similar between men and women [1]6]. Ideally a large population-based study involving direct polysomnography is needed to clarify any sex differences in risk factors for sleep-disordered breathing.

The prevalence of the sleep-disordered breathing outcomes in the sample we analysed, including sleep apnoea, is consistent with those reported in other large studies $[8,1 \underline{5,284}, 25]$. Sleep apnoea can present itself as obstructive, central or 
"mixed" (obstructive/central) in nature. Although the word 'obstructive' was not included in the sleep history questionnaire in the MESA, the prevalence of central and mixed sleep apnoea is much rarer in the general population than is obstructive sleep apnoea [2 $\underline{6} 3]$. Therefore, it is likely that the vast majority of cases of diagnosed sleep apnoea in the present study are obstructive in nature.

The present study findings support the hypothesis that low levels of physical activity increase the severity of sleep-disordered breathing. One possible causal pathway for this hypothesis involves a bidirectional influence of obesity (Figure 1). A habitual slow walking pace may, over time, contribute to weight gain, which is an independent risk factor for sleep-disordered breathing [2018]. Conversely, it is possible that more severe sleep-disordered breathing mediates more daytime sleepiness and, therefore, a decreased willingness or propensity for a faster walking pace. This pathway is supported by population-based research, which has found a statistically significant association between tiredness and a decreased walking speed [2으]. Because BMI is on this potential causal pathway, we did not adjust for it in our primary analysis of risk differences. Nevertheless, in our secondary analysis, slow walking pace was compared against other items, including $\mathrm{BMI}_{2}$ on popular screening tools for sleep-disordered breathing, including BMI. Slow walking pace was found to be independently associated with the prevalence of diagnosed sleep apnoea, with a point estimate prevalence risk ratio that was slightly larger than those relating to sex, daytime tiredness and hypertension. The $95 \%$ Cis of these latter risk fatios also-overlapped 1 . This finding was consistent even if the participants who reported no walking at all were removed from the analysis. In terms of clinical relevance, the point estimate for the prevalence risk ratio for walking speed 
represents a moderate effect size, but the uncertainty (quantified by the $95 \% \mathrm{Cl}$ ) is such that the true population effect could be trivial $(<1.11)$ to large $(>2)$.

It is plausible that the causal pathway between walking speed and sleep-disordered breathing involves exercise-specific mechanisms, independent of BMI (Figure 1) [10, 179, 16]. It has been postulated that being physically active increases upper airway dilator muscle strength, reduces nasal resistance, improves sleep architecture and prevents lower-extremity fluid accumulation - the so called 'Rostral Fluid Shift' hypothesis [1를. All of these exercise-mediated changes may help to maintain airway patency during sleep and improve sleep-disordered breathing [110]. The rostral shift hypothesis has received considerable attention recently [1ㅍz] , and proposes that sedentary living leads to increased fluid accumulation in the legs during the daytime, which then shifts to the rostrum (towards the head) when lying supine for sleep. It is proposed that this fluid shift increases the propensity for upper airway collapse [1무].

In the MESA, only 4205 people answered the question relating to loudness of snoring, with 1526 participants reporting 'don't know'. The response rate for selfreported perceptions of apnoea during sleep was also poor (Table 2). In contrast, $6125(98 \%)$ of the 6232 participants assessed at exam 2 were able to answer the walking speed question. Therefore, not only might the association between walking speed and sleep apnoea be stronger than other proposed risk factors, the question may be more easily-answered by participants than these other risk factors, e.g. daytime tiredness. 
The large sample of our study, together with the fact that statistically significant associations were present, indicates acceptable statistical power. Nevertheless, aA limitation of our study is that it was observational and cross-sectional in nature, with temporal risk of bias.- Therefore, we can only speculate, as we have done above, about proposed causal mechanisms. A related limitation is that confounding in ebservational studies bias a risk ratio by as much as 2-3-fold [21]. Nevertheless However, our finding that walking speed (an indicator of physical activity and general frailty) that an exposure related to the propensity for physical activity is associated with less severe sleep-disordered breathing, independent from $\mathrm{BMI}_{2}$ agrees with the results of recent randomised controlled trials of supervised exercise interventions [109].

In conclusion, we report an independent association between self-reported slowwalking speed and sleep-disordered breathing outcomes in a large population-based study. Prospective observational and experimental studies should follow to confirm these findings. We propose that a simple yes/no question relating to slow walking speed could improve the screening utility of the STOP-Bang questionnaire.

\section{References}

1. Aron A, Zedalis D, Gregg JM, Gwazdauskas FC, Herbert WG. Potential clinical use of cardiopulmonary exercise testing in obstructive sleep apnea hypopnea syndrome. Int J Cardiol 2009; 132: 176-186

Georg Thieme Verlag KG. P. O. Box 3011 20, D-70451 Stuttgart, Germany. http://www.thieme.de/fz/sportsmed/index.html 
2. Barros AJ, Hirakata VN. Alternatives for logistic regression in cross-sectional studies: an empirical comparison of models that directly estimate the prevalence ratio. BMC Med Res Methodol 2003; 3: 21

3. Bild DE, Bluemke DA, Burke GL, Detrano R, Diez Roux AV, Folsom AR, Greenland P, Jacobs Jr DR, Kronmai R, Liu K, Clark Nelson J, O'Leary D, Saad MF, Shea S, Szklo M, Tracy RP. Multi-Ethnic Study of Atherosclerosis: Objectives and Design. Am J Epidemiol 2002; 156: 871- 881

4. Cesari M, Kritchevsky SB, Penninx BW, Nicklas BJ, Simonsick EM, Newman AB, Tylavsky FA, Brach JS, Satterfield S, Bauer DC, Visser M, Rubin SM, Harris TB, Pahor M. Prognostic value of usual gait speed in well-functioning older people-results from the Health, Aging and Body Composition Study. J Am Geriatr Soc 2005; 53: 1675-1680

5. Chung F, Subramanyam R, Liao P, Sasaki E, Shapiro C, Sun Y. High STOPBang score indicates a high probability of obstructive sleep apnoea. Br J Anaesth 2012; 108: 768-775

6. Chung F, Chau E, Yang Y, Liao P, Hall R, Mokhlesi B. Serum bicarbonate level improves specificity of STOP-Bang screening for obstructive sleep apnea. Chest 2013; 143: 1284-1293

7. Endeshaw YW, Unruh ML, Kutner M, Newman AB, Bliwise DL. Sleep-disordered breathing and frailty in the Cardiovascular Health Study Cohort. Am J Epidemiol 2009; 170: 193-202

8. Enright PL, Newman AB, Wahl PW, Manolio TA, Haponik EF, Boyle PJ. Prevalence and correlates of snoring and observed apneas in 5201 older adults. Sleep 1996; 19: 531-538 


\section{Harriss DJ, Atkinson G. Ethical standards in sport and exercise science}

\section{research: 2014 update. Int J Sports Med 2013; 34: 1025-1028}

9.10. Iftikhar IH, Kline CE, Youngstedt SD. Effects of exercise training on sleep apnea: A meta-analysis. Lung 2014; 192: 175-184

10.11. Kline CE, Crowley EP, Ewing GB, Burch JB, Blair SN, Durstine JL, Davis JM, Youngstedt SD. The effect of exercise training on obstructive sleep apnea and sleep quality: A randomized controlled trial. Sleep 2011; 34: 1631-1640

11.12. Lattimore JL, Celermajer DS, Wilcox I. Obstructive sleep apnea and cardiovascular disease. J Am Coll Cardiol 2003; 41: 1429-1437

12.13. Mirrakhimov AE. Physical exercise related improvement in obstructive sleep apnea. Look for the rostral fluid shift. Med Hypotheses 2013; 80: 125-128

13.14. Mutter TC, Chateau D, Moffatt M, Ramsey C, Roos LL, Kryger M. A matched cohort study of postoperative outcomes in obstructive sleep apnea.

Anesthesiology 2014; 121:707-718

14.15. Pallesen S, Nordhus IH, Omvik S, Sivertsen B, Tell GS, Bjorvatn B. Prevalence and risk factors of subjective sleepiness in the general adult population. Sleep 2007; 30: 619-624

15.16. Pataka A, Daskalopoulou E, Kalamaras G, Fekete Passa K, Argyropoulou P. Evaluation of five different questionnaires for assessing sleep apnea syndrome in a sleep clinic. Sleep Med 2014; 15: 776-781

16.17. Peppard PE, Young T. Exercise and sleep-disordered breathing: An association independent of body habitus. Sleep 2004; $27: 480-484$

18. Qaseem A, Dallas P, Owens DK, Starkey M, Holty JC, Shekelle P. Diagnosis of obstructive sleep apnea in adults: A clinical practice guideline 
from the American College of Physicians. Ann Intern Med 2014; 161: 210$\underline{220}$

17.19. Redolfi S, Yumino D, Ruttanaumpawan P, Yau B, Su MC, Lam J, Bradley TD. Relationship between overnight rostral fluid shift and Obstructive Sleep Apnea in nonobese men. Am J Respir Crit Care Med 2009; 179: 241-246

18.20. Riad W, Chung F. Preoperative screening for obstructive sleep apnea in morbidly obese patients. Int Anesthesiol Clin 2013; 51: 13-25

\section{Ryan PJ, Hilton MF, Boldy DAR, Evans A, Bradbury S, Sapiano S, Prowse} $\underline{K}$, Cayton RM. Validation of British Thoracic Society guidelines for the diagnosis of the sleep apnoea/hypopnoea syndrome: can polysomnography be avoided? Thorax 1995; 50: 972-975

19.22. Stanaway FF, Gnjidic D, Blyth FM, Le Couteur DG, Naganathan V, Waite L, Seibel MJ, Handelsman DJ, Sambrook PN, Cumming RG. How fast does the Grim Reaper walk? Receiver operating characteristics curve analysis in healthy men aged 70 and over. BMJ 2011;343:d7679 doi: 10.1136/bmj.d7679

20.23. Stenholm S, Kronholm E, Sainio P, Borodulin K, Era P, Fogelholm M, Partonen T, Porkka-Heiskanen T, Koskinen S. Sleep-related factors and mobility in older men and women. J Gerontol A Biol Sci Med Sci 2010; 65: 649-657

\section{Syddall HE, Westbury LD, Cooper $C$, Sayer AA. Self-reported walking} speed: A useful marker of physical performance among communitydwelling older people? JAMDA: http://dx.doi.org/10.1016/j.jamda.2014.11.004

21. Taubes G, Mann CC. Epidemiology faces its limits. Science 1995; 269: 164-169 22.25. Vasquez MM, Goodwin JL, Drescher AA, Smith TE, Quan SF. Associations of 
dietary intake and physical activity with sleep disordered breathing in the apnea positive pressure long-term efficacy study (APPLES). J Clin Sleep Med 2008; 4: $411-418$

23.26. White $L H$, Bradley TD. Role of nocturnal rostral fluid shift in the pathogenesis of obstructive and central sleep apnoea. J Physiol 2013; 591: 1179-1193

24.27. Yeboah J, Redline S, Johnson C, Tracy, R, Ouyang P, Blumenthal RS, Burke GL, Herrington DM. Association between sleep apnea, snoring, incident cardiovascular events and all-cause mortality in an adult population: MESA. Atherosclerosis 2011; 19: 963-968

25.28. Young T, Palta M, Dempsey J, Skatrud J, Weber S, Badr S. The occurrence of sleep-disordered breathing among middle-aged adults. N Engl J Med 1993; 328: $1230-1235$

\section{Graphic Legend}

Figure 1: The potential causal pathway(s) between physical activity and severity of sleep-disordered breathing. 
Table 1. Characteristics of the slow and average/brisk walkers at examination two in the MESA sample.

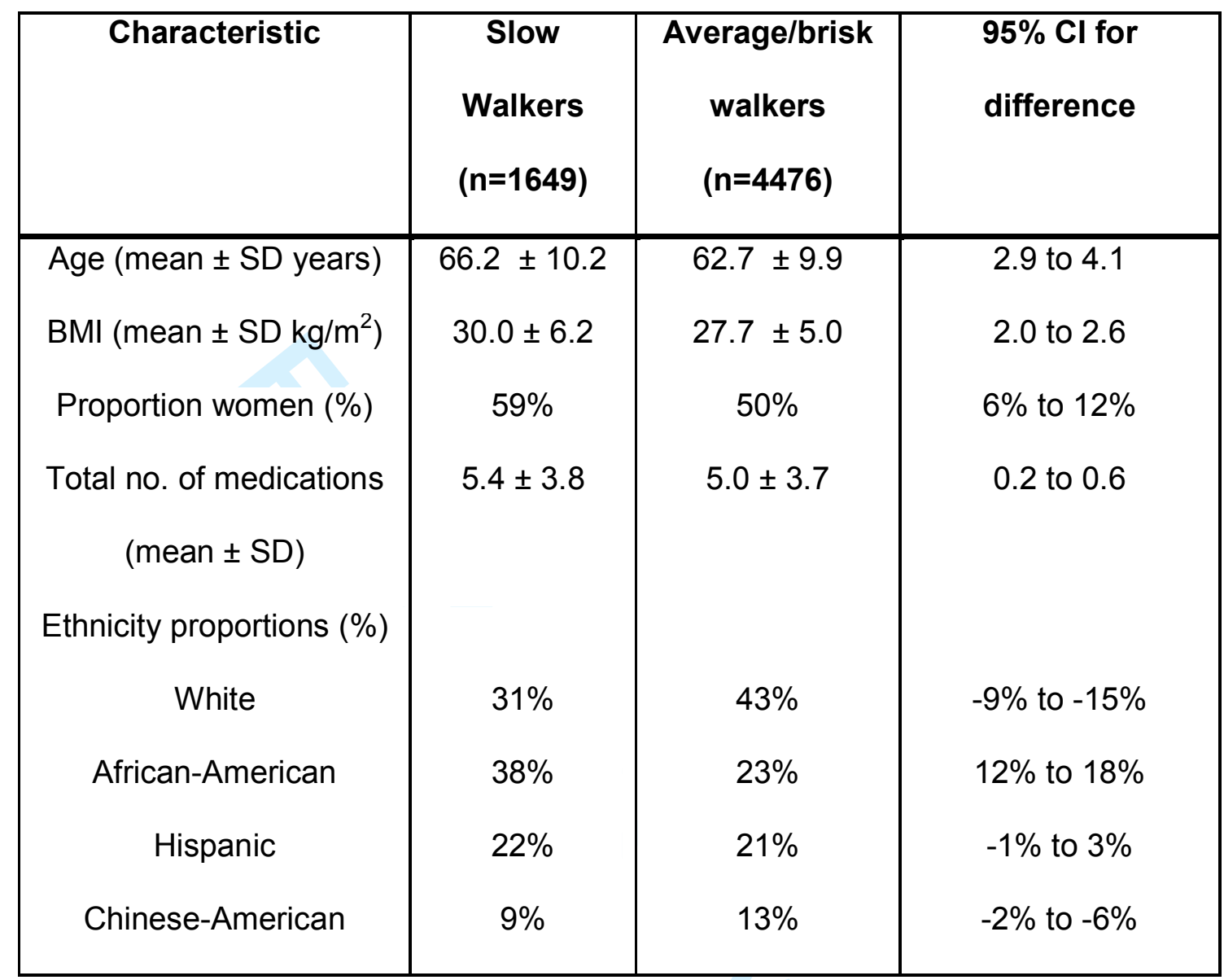


Table 2. The prevalence of sleep-disordered breathing outcomes in men, women and the overall MESA sample.

\begin{tabular}{|c|c|c|c|}
\hline $\begin{array}{l}\text { Sleep-disordered } \\
\text { breathing } \\
\text { outcome }\end{array}$ & $\begin{array}{l}\text { Prevalence in } \\
\text { Men }\end{array}$ & $\begin{array}{l}\text { Prevalence in } \\
\text { women }\end{array}$ & $\begin{array}{c}\text { Overall prevalence } \\
\qquad \mathbf{N}(\%)\end{array}$ \\
\hline $\begin{array}{c}\text { Physician- } \\
\text { diagnosed sleep } \\
\text { apnoea }\end{array}$ & 140 / 2912 (4.8\%) & 73 / $3213(2.3 \%)$ & 213 / 6125 (3.5\%) \\
\hline $\begin{array}{l}\text { Self-reported } \\
\text { apnoeas }\end{array}$ & $240 / 2168(11.0 \%)$ & 138 / 2335 (5.9\%) & 378 / 4503 (8.4\%) \\
\hline Loud snoring & 347 / $1472(23.6 \%)$ & 204 / 1207 (16.9\%) & $551 / 2679(20.5 \%)$ \\
\hline Daytime tiredness & 637 / $2950(21.6 \%)$ & 740 / $3245(22.8 \%)$ & 1377 / 6195 (22.2\%) \\
\hline
\end{tabular}

\footnotetext{
${ }^{1}$ The denominators vary for different outcomes depending on the number of 'don't know' responses to each STOP-Bang question.
} 
Table 3. Multivariable-adjusted risk differences between slow and average/brisk walkers for sleep-disordered breathing.

\begin{tabular}{|c|c|c|c|c|}
\hline Study outcome & $\begin{array}{c}\text { Risk ('slow' } \\
\text { walking speed) }\end{array}$ & $\begin{array}{c}\text { Risk } \\
\text { ('average/brisk' }\end{array}$ & difference & $\begin{array}{c}\text { Confidence } \\
\text { walking speed) }\end{array}$ \\
\hline $\begin{array}{c}\text { Diagnosed sleep } \\
\text { apnoea }\end{array}$ & $4.7 \%$ & $3.2 \%$ & $1.5 \%$ & $0.4 \%$ to $2.5 \%$ \\
Self-reported & $10.7 \%$ & $8.7 \%$ & $2.0 \%$ & $0.1 \%$ to $3.8 \%$ \\
apnoeic events & & $20.1 \%$ & $4.8 \%$ & $1.2 \%$ to $8.3 \%$ \\
Loud snoring & $24.9 \%$ & $21.0 \%$ & $5.4 \%$ & $3.0 \%$ to $7.8 \%$ \\
\hline Daytime tiredness & $26.4 \%$ & & & \\
\hline
\end{tabular}

\footnotetext{
${ }^{1}$ Multivariable risk differences were similar across ethnic groups; for men and women; when people who reported no walking at all were removed from the analysis.
} 
Table 4: Multivariable-adjusted prevalence risk ratios for the slow walking speed question and other yes/no questions traditionally included on screening tools such as the STOP-Bang tool.

\begin{tabular}{|c|c|c|c|}
\hline STOP-Bang variable & $\begin{array}{c}\text { Prevalence } \\
\text { risk ratio }\end{array}$ & \multicolumn{2}{|c|}{ interval } \\
\hline $\begin{array}{c}\text { Stopping breathing } \\
\text { during sleep }\end{array}$ & 21.9 & 12.6 & 38.0 \\
Loud snoring & 2.1 & 1.5 & 3.1 \\
BMI & 1.7 & 1.2 & 2.5 \\
Slow walking speed & 1.5 & 1.0 & 2.1 \\
Daytime tiredness & 1.3 & 1.0 & 1.8 \\
Sex & 1.3 & 0.8 & 1.9 \\
High blood pressure & 1.2 & 0.9 & 1.7 \\
\hline
\end{tabular}




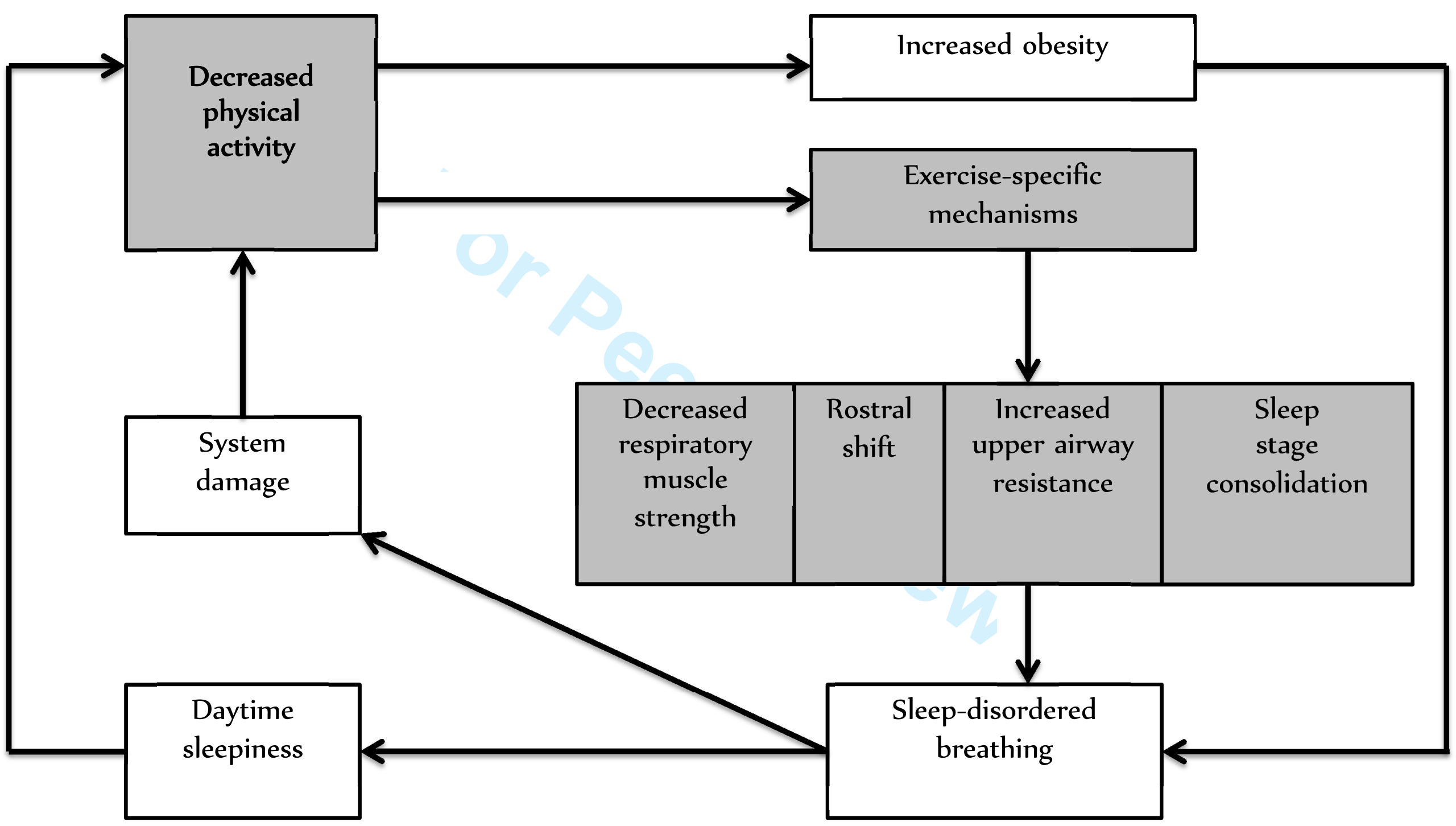

